\title{
Will Climate Change Increase Inequality in Wage Growth? -Evidence from China's 30 Provincial Capitals
}

\section{Hanxiao Xu}

Ocean University of China - Laoshan Campus: Ocean University of China

\section{Qiang Gao}

Ocean University of China - Laoshan Campus: Ocean University of China

Bin Yuan ( $\nabla$ yuanbin1221@126.com)

Ocean University of China - Laoshan Campus: Ocean University of China https://orcid.org/0000-00032533-152X

\section{Research Article}

Keywords: Climate change, Wet bulb globe temperature index (WBGT), Wage income growth, Relative poverty

Posted Date: October 6th, 2021

DOl: https://doi.org/10.21203/rs.3.rs-776364/v1

License: (9) This work is licensed under a Creative Commons Attribution 4.0 International License. Read Full License 


\section{Will climate change increase inequality in wage growth?

\author{
-evidence from China's 30 provincial capitals
}

4 Hanxiao Xu • Qiang Gao • Bin Yuan*

6 Received: date / Accepted: date

7 Abstract Examining the impact of long-term temperature rise on wages is 8 not only beneficial for gaining insight into the economic consequences of cli9 mate change, but also of great reference value to reduce income disparity and - alleviate relative poverty. Based on the panel data of 30 provincial capitals 1 from 1996-2018, the Wet Bulb Globe Temperature (WBGT) is adopted in 12 this paper to conduct an empirical analysis of temperature rises' impact on 3 wage in various industries. It is found that, firstly, temperature rise will signif14 icantly reduce the growth of wage and show heterogeneity. Among them, the 15 growth of wage in the manufacturing industry is most prominently affected by rising annual average temperatures. Second, in terms of seasonal differences, the negative impact of temperature rise on wage growth is mainly in summer. Different temperature swings and different vulnerability producers demonstrate lead to largely dissimilar marginal impacts of temperature rise in different regions. Wages in relatively vulnerable regions and regions with relatively sharp temperature fluctuations are more significantly affected by the increase in average summer temperatures. Thirdly, in the long run, the negative impact of annual average temperature increases on the wages of agriculture industries shows a notable cumulative effect, which mainly comes from the irreversible impact of temperature increase on labor productivity, and will further widen the income gap between regions. Based on the above findings,

Hanxiao $\mathrm{Xu}$

College of Management, Ocean University of China, No.238 Songling Rd, Qingdao, 266100, Shandong, China

Qiang Gao

College of Management, Ocean University of China, No.238 Songling Rd, Qingdao, 266100, Shandong, China

Bin Yuan*

E-mail: yuanbin1221@126.com

College of Management, Ocean University of China, No.238 Songling Rd, Qingdao, 266100, Shandong, China 
this paper proposes targeted strategies from two dimensions, "mitigation" and "adaptation", in order to narrow the regional income gap and achieve balanced development, and to provide theoretical references for subsequent policies responding to climate change.

Keywords Climate change - Wet bulb globe temperature index (WBGT) . Wage income growth · Relative poverty

\section{Introduction}

Today, climate change and its associated gradual slow-onset and extreme sudden-onset weather events have become one of the greatest challenges to human natural systems. As a sensitive region to global climate change, China has been witnessing an annual average temperature rise of $0.24^{\circ} \mathrm{C}$ per decade. The rate is notably higher than the global average during the same period, accompanying of which is a significant rise of the number of extreme high temperatures and heavy precipitation events (Zhang et al., 2020). According to the IPCC assessment report, high temperature will be more frequent and stronger in the future, with intensified impact on ecological environment and human socio-economic activities(Masson-Delmotte et al., 2018). In this context, although some industries are benefiting from climate change (due to e.g., rising temperatures and increased precipitation)(Somanathan et al., 2021), most industries (e.g., agriculture, construction, and other climate-sensitive industries) are adversely affected by global warming (Pachauri et al., 2014). Meanwhile, due to different temperature swings and different vulnerability of each producer across regions, the heterogeneous impacts caused by climate change will fall disproportionately on workers in all industries of all regions, which may eventually develop into a new source of income growth inequality (Deschênes and Greenstone, 2007). Therefore, as China enters the "post-poverty alleviation era", it is important to clarify the heterogeneous impact of climate change on the growth of workers' wages, so that government bodies will make more precise adaptation policies to increase society's resilience to climate change, take into account the relative poverty in policy implementation, and avoid further widening of the income gap between regions and industries.

To address the above theoretical and practical issues, this paper, from the perspective of temperature rises identifies the effects of climate change on wages in different industries and its heterogeneous sources by estimating the effect of temperature change ${ }^{1}$, with the aim of achieving an integrated approach to address climate change and relative poverty. Compared with the

1 The main reason for this paper to select temperature rises as the research perspective is after a consideration of the difference between temperature change and climate change. While the latter represents a long-term transformation, temperature change, being shortterm, is the most direct and widest manifestation of climate change. Generally, the climate can be understood as the distribution function of the temperature. As climate itself is a distribution of multi-dimensional variables consisting of temperature, precipitation and wind, an accurate description of climate change must involve complex measurements on those dimensions, i.e., to measure the independent and joint distributions of multiple variables 
existing studies, the possible marginal contributions of this paper are: (1) to expand the research scope on climate change by exploring the pathways and degrees of the impact brought by temperature rises on wages; (2) to improve the accuracy of the research results by adopting the WBGT index to measure temperature variables ${ }^{2}$. Compared with the prior studies that consider temperature as the only element (Zhang et al., 2018), this paper uses the historical average temperature of each region as the reference and the WBGT index as the temperature variable. While considering how high temperature and humidity affect body heat stress, the paper takes into account regional and seasonal climate conditions to improve the accuracy and persuasiveness of the estimated research findings; (3) to further improve the precision of the findings and recommendations for policies by identifying the heterogeneous sources of the impact of temperature rises on wage growth from two dimensions, namely, vulnerability and temperature fluctuation.

\section{Literature review}

Since the 1980s, global climate change has become increasingly prominent and has attracted wide attention from scholars at home and abroad (Sachs, 2003; Iyigun et al., 2017). In recent years, a large body of literature has argued the relationship between climate change and overall economic output at the macro level (Dell et al., 2012), and further examined the impact of climate change on the output (value) in sectors such as agriculture, manufacturing, and tourism (Cai et al., 2018; Burke et al., 2015). While most scholars have basically reached a consensus that climate change in the form of rising average temperatures represents a negative impact on economic growth (Heal and Park, 2013), some literature presents an opposite conclusion, demonstrating that climate change had beneficial economic effects, such as a $3-4 \%$ increase in per capita income in cold countries for every $1^{\circ} \mathrm{C}$ increase in average annual temperature (Heal and Park, 2013). Moreover, there is no academic consensus on whether the economic consequences caused by climate change mainly affect developed or backward regions. Comparatively, more studies have concluded that the negative impacts of climate change are mainly found in backward regions rather than developed regions (Letta et al., 2018). The main reason for this heterogeneity is that the negative impacts of climate change depend

(such as those between wind and precipitation). However, in practice, it is often difficult for researchers to consider all the dimensions (mean, variance, covariance, extreme values, among others), therefore they tend to be able to investigate the effects caused by changes in only one (or several) meteorological factors to identify the impact of climate change. For example, looking at the economic effects of changes in average temperature (while controlling average precipitation) is only a rough description of (the multidimensional) climate change. As climate (change) economics develops, the controlled variables and statistical dimensions in econometric models are gradually increasing in numbers, thus the description of climate change is becoming more and more accurate.

2 Wet Bulb Globe Temperature (WBGT) index is the most commonly used index that comprehensively considers temperature and humidity to measure heat stress, and represents the heat intensity of body exposure to the environment. 
to a certain extent on the mitigation and adaptation measures adopted by the disaster-bearers(Brysse et al., 2013). Some literature, on the other hand, has pointed out that no significant differences of productivity losses caused by climate change have been seen between developed and backward regions (Brysse et al., 2013), or that the economic consequences of climate change have a greater impact on developed regions (Ramsey and Kwon, 1992). As research progresses, some scholars have explored the negative effects of climate change on the physical and mental health of individual workers from a microscopic perspective (Branco and Féres, 2021). For example, high temperatures cause stress, which can lead to reduced attention and cognitive abilities, among others (Krüger and Neugart, 2018). Temperature fluctuations may further affect labor productivity and work time allocation, and act as direct or indirect transmission mechanisms on the output of each production sector(Parsons, 2007).

A review of the past literature found that detailed studies have been done on the impact of climate change on the economy, but there is still room for further improvement. First, although studies have explored the impact of climate change on industries such as agriculture, manufacturing, and real estate (Kompas et al., 2018), most of them have focused on the total output (value) of the whole industry, and few on the wages, especially income inequality, of workers. As wage is currently important source of income for people, exploring the heterogeneous effects of climate change on it is important for narrowing the income gap between industries and regions in China and for alleviating relative poverty. Second, it is still under debate whether climate change will cause negative impacts, and whether the negative impacts will mainly exist in backward or developed regions, which will directly affect the fairness and inclusiveness of climate and governance-related policies.

\section{Theoretical analysis}

To better clarify the impact of temperature rise on wages, this paper draws a logic diagram for analyzing the differences in the damage caused by temperature rise and its impact under different scenarios (Fig.1). Among them, (a) (b) in Fig.1 presents the intrinsic linkage between the level of wages $Q$, the degree of temperature fluctuation $W$, and the loss of wages $D$, respectively. When the increase in temperature is at $W_{1}$, the optimal level of wages (under the condition of maximizing workers' benefits) is $Q$. Excessively cold or hot temperatures make it impossible for workers to concentrate on their work and may damage their health, resulting in a decrease in marginal labor productivity (or an increase in marginal cost of labor) and a decrease in work time. In particular, the labor productivity of outdoor workers will be significantly reduced due to loss of labor capacity under heat waves (such as fatigue and reduced muscle endurance) (González-Alonso et al., 1999). At the same time, heat stress will also lead to a loss of productivity due to reduced attention, cognitive abilities and low-quality decision making among indoor workers (Orlov et al., 2020). 
In this scenario, workers, as rational economic men, will adjust labor input to maximize utility according to the current climate state. Therefore, in the short run, with factor prices and labor supply and demand remain constant, while temperature rise intensifies, i.e., when the temperature compared with the historical average increases from $W_{1}$ to $W_{2}$, the marginal output value of labor factors keeps decreasing due to the negative temperature shock, while the marginal cost curve of factors increases from $M C_{1}$ to $M C_{2}$. At this point, based on the objective to maximize utility, workers will inevitably further reduce their labor input, and thus deviate from the optimal factor input $W_{1}$. As a result, affected by changes in the input of labor factors, the output will decline, followed by a downward trend in wages.

However, the negative impact of rising temperatures on wages usually varies in accordance with the degree of temperature fluctuations and the vulnerability of industries and individuals ${ }^{3}$.First, in terms of the marginal damage of temperature rise as in Fig. 1(b), its impact on wages usually shows a gradual increase (Schlenker et al., 2006). Thus, for workers in different regions (with different degrees of temperature rises), the temperature rise will likely cause and even further the inter-regional wage gap. Second, in terms of the vulnerability shown in each industry and individual, on the one hand, as industries have different exposure levels in their production environments and different capacities to adapt, temperature rises will lead to differentiated effects, which in turn will affect the marginal damage of temperature rise (Polsky et al., 2007). For example, under the same scenario, the productivity and work hours of indoor workers are less affected by the negative impact of temperature rise than those of outdoor workers due to air conditioning and lower work intensity; on the other hand, temperature rises also affects differently across workers in the same industry as they are dissimilarly vulnerable to it. Workers with higher income and assets are more likely to be adaptable through defensive investments compared to poorer groups (workers with relatively lower income and assets). For example, high-income workers are able to improve their work environment in response to climatic conditions (Olmstead and Rhode, 2011), or to relocate from areas with high exposure to negative climatic impacts, so as to minimize the potential adverse effects of rising temperatures on their wages.Thus, workers in less exposed industries and those with higher climate adaptation capacities can effectively dampen the negative impact of rising temperatures on their wages. As depicted in Fig.1(c), for workers $n$ and workers $m$ with different levels of vulnerability, the marginal damage curve for workers $\mathrm{m}$ (with lower vulnerability) is significantly lower than that for workers $n$. At this point, even under the same temperature fluctuation, the marginal damage of temperature increase on workers $n$ and workers $m$ is still different due to the difference in the vulnerability in industries and individuals, which leads to a $D_{L m}-D_{L n}$ wage gap.

3 According to the integrated VSD model on climate change vulnerability proposed by Polsky et al. (2007), the vulnerability assessment system for workers to deal with weather risks mainly includes three dimensions: exposure, sensitivity, and adaptability of disasterbearers. 


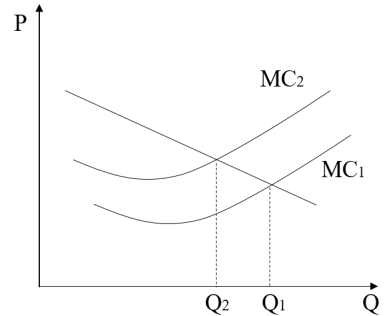

(a)

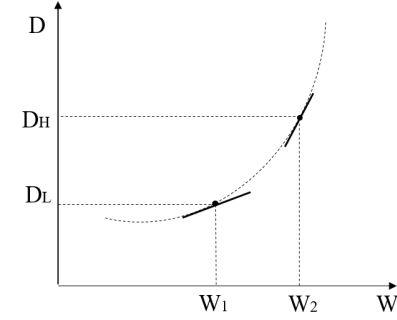

(b)

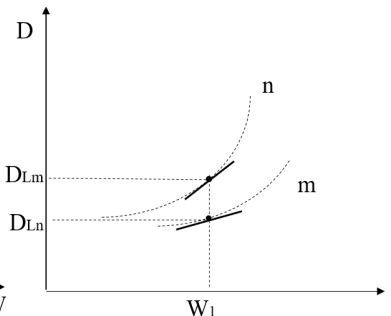

(c)

Fig. 1 Differences in marginal damage of temperature rise and its effects under different scenarios

Based on the theoretical model of Bond et al. (2010), combined with the abovementioned pathways and mechanisms of the impact of temperature rise on wages, the theoretical model in this paper is constructed as follows.

$$
Y_{i t}=\left(e^{\beta \Delta T_{i t}} L_{i t}\right) A_{i t}
$$

$$
\Delta A_{i t}=g_{i}+\gamma_{0} \Delta T_{i t}+\ldots+\gamma_{n} \Delta T_{i t-n}
$$

where $Y$ denotes wages; $L$ denotes work hours; $A$ denotes labor productivity; $\Delta T$ denotes the fluctuation degree of temperature, and $\beta$ and $\gamma$ represents the degree of impact of temperature rise on labor input time and labor productivity, respectively. In a stable market environment, i.e., when $L_{i t}=L_{i}$, the wage of region $i$ will keep growing steadily at the level of $g_{i}$ when it is not hit by the temperature rise. Given the lagged effect of temperature rise and the constraint and influence of human capital accumulation on the output, the following dynamic growth model can be obtained after simplifying and differencing Equ.1.

$y_{i t}=\beta_{0} \Delta T_{i t}+A_{i t}+L_{i t}+\alpha_{1} y_{i t-1}+\ldots+\alpha_{n} y_{i t-n}+\beta_{1} \Delta T_{i t-1}+\ldots+\beta_{n} \Delta T_{i t-n}+\varepsilon_{i t}$

In Equ.3, $y_{i t}$ and $L_{i t}$ are the logarithmic forms of wages and labor factor input, respectively. Again, assuming that the external market environment remains unchanged in the short run, the wage growth $\Delta y_{i t}$ within time period $t$ of the individual $i$ can be obtained based on Equ.2 and Equ.3;

$$
\begin{aligned}
\Delta y_{i t}= & g_{\mathrm{i}}+\alpha_{1} \Delta y_{i t-1}+\cdots+\alpha_{n} \Delta y_{i t-n}+\left(\gamma_{0}+\beta_{0}\right) \Delta T_{i t}+\left(\gamma_{1}+\beta_{1}-\beta_{0}\right) \Delta T_{i t-1} \\
& +\cdots+\left(\gamma_{n}+\beta_{n}-\beta_{n-1}\right) \Delta T_{i t-n}-\beta_{n} \Delta T_{i t-n-1}+\Delta \varepsilon_{i t}
\end{aligned}
$$

In most cases, there is no significant correlation between wage growth in different time periods (Dell et al., 2012). Therefore, to further investigate the effect of temperature rise on wages, this paper assumes that the degree of temperature fluctuation and the level of wage growth remain constant, i.e., $\Delta y_{i t-j}=\Delta y_{i}$. Define $\rho$ as the estimated coefficient of the effect of rising temperatures on wage.The effect of temperature rise on wages can be obtained 
based on Equ.4:

$$
\Delta y_{i}=\frac{g_{i}}{1-a_{1}-\ldots-a_{n}}+\frac{\sum_{j=0}^{n+1} \rho_{j}}{1-a_{1}-\ldots a_{n}} \Delta T_{i}
$$

If only the effect of rising temperatures in the current period is considered, i.e. $\Delta A_{i t}=g_{i}+\gamma_{0} \Delta T_{i t} ; y_{i t}=\beta_{0} \Delta T_{i t}+A_{i t}+L_{i t}+\varepsilon_{i t}$, then Equ. 5 can be further abbreviated as

$$
\Delta y_{i t}=g_{i}+\left(\gamma_{0}+\beta_{0}\right) \Delta T_{i t}-\beta_{0} \Delta T_{i t-1}
$$

where $\Delta y_{i t}$ denotes the wage growth. According to the above equation, when the temperature returns to the normal level, its average effect on work hours will be reversed. For example, although an increase in climate warming reduces work hours, when the temperature returns to its average, workers' labor input time returns to its normal level. Conversely, the effect on labor productivity does not reverse with the recovery of the temperature. This also indicates that rising temperatures have a cumulative effect on wage growth. An increase in temperature over a period of time may lead to a prolonged period of low wages for workers, resulting in a further widened gap between the rich and the poor.

\section{Model construction and data description}

\subsection{Empirical model}

Based on the above theories, this paper intends to construct the following econometric regression model to identify the impact of rising temperatures on wage growth in each industry.

$$
g_{i t}=\sum_{j=0}^{K} \rho_{j} \Delta T_{i t-j}+\theta_{i}+\theta_{r t}+\varepsilon_{i t}
$$

where $T$ denotes the degree of temperature increase with a period lag $K ; \theta_{i}$ denotes the region fixed effect; $\theta_{r t}$ denotes the time fixed effect, including the dummy variables and differences between regions; $\varepsilon_{i t}$ is the error term. Based on the previous theoretical model, $a_{i}=0$ needs to be satisfied as the precondition for an econometric analysis with Equ.6. Therefore, on the basis of testing the correlation between wage growth at different time periods, this paper further considers the linear correlation between the random disturbance term $\Delta \varepsilon_{i t}$ in Equ.4 and the lag of growth $\Delta y_{i t-1}$, and chooses the extended lag as the instrumental variable of the growth $\Delta y_{i t-1}$ for robustness testing. In addition, in order to further identify and clarify the heterogeneity of the impact of temperature rise on each industry and its sources, this paper introduces in Equ. 8 the interaction terms of the vulnerability of workers under temperature rises and weather risks and the degree of temperature fluctuations, respectively. Among them, in terms of vulnerability, income is the most important 
Table 1 Relevance statistics

\begin{tabular}{|c|c|c|c|c|c|}
\hline Industries & Lag period & $g$ & L1.g & L2.g & L3.g \\
\hline \multirow{4}{*}{ Agriculture } & $g$ & 1 & & & \\
\hline & L1.g & $-0.174^{* * *}$ & 1 & & \\
\hline & L2.g & $-0.071^{*}$ & $-0.183^{* * *}$ & 1 & \\
\hline & L3.g & -0.003 & -0.065 & $-0.192^{* * *}$ & 1 \\
\hline \multirow{4}{*}{ Construction } & $g$ & 1 & & & \\
\hline & L1.g & $-0.293^{* * *}$ & 1 & & \\
\hline & L2.g & 0.008 & $-0.297^{* * *}$ & 1 & \\
\hline & L3.g & $0.290^{* * *}$ & $-0.090^{* *}$ & $0.046^{*}$ & 1 \\
\hline \multirow{4}{*}{ Manufacturing } & $g$ & 1 & & & \\
\hline & L1.g & $-0.418^{* * *}$ & 1 & & \\
\hline & L2.g & -0.025 & $-0.417^{* * *}$ & 1 & \\
\hline & L3.g & -0.018 & -0.027 & $-0.419^{* * *}$ & 1 \\
\hline \multirow{4}{*}{ Finance } & $g$ & 1 & & & \\
\hline & L1.g & $-0.236^{* * *}$ & 1 & & \\
\hline & L2.g & 0.042 & $-0.243^{* * *}$ & 1 & \\
\hline & L3.g & 0.018 & 0.031 & $-0.249^{* * *}$ & 1 \\
\hline
\end{tabular}

$g_{i t}=\sum_{j=0}^{K} \rho_{j} \Delta T_{i t-j}+\sum_{j=0}^{K} \rho_{j} \Delta T_{i t-j} \times p o o r+\sum_{j=0}^{K} \rho_{j} \Delta T_{i t-j} \times h i g h+\theta_{i}+\theta_{r t}+\varepsilon_{i t}$

factor reducing workers' exposure and sensitivity, and helping adopt adaptive measures. Workers with higher income and assets are able to minimize the possible adverse effects of weather shocks on them through ex ante and ex post defensive investments (Sesmero et al., 2018). Therefore, in this paper, the average level of wages of workers in each industry is chosen as a measure, defined in the form of a dummy variable, i.e., regions where wages in each industry is lower than the sample mean are defined as relatively vulnerable regions, defined as poor $=1$, otherwise taken as 0 . In terms of temperature fluctuations, this paper also uses a dummy variable, defining regions where the current temperature fluctuation value is higher than the sample mean as regions with high temperature fluctuations (high), defined as high $=1$, otherwise taken as 0 . This results in an estimation model on the heterogeneous impacts of temperature rise on wage growth:

In addition, based on the above theoretical model Equ.4, it is known that before the estimation of the econometric model, the correlation between wage growth in different lags needs to be tested, and the specific correlation coefficient estimation results are shown in Table. 1. Different from the previous hypothesis, there is a significant negative correlation between the wage growth in the current period and that in lag- 1 in different industries. The possible reason for this is that the wage growth in the current period attracts a large number of workers to move to the industry, leading to a significant increase in labor supply in the industry. In the case of unchanged labor demand, the labor market in the industry will have more supply than demand, which leads to a decrease in wages, thus showing a significant negative correlation between the 
increase in wages in the current period and the increase in the lag. Combining the research findings from home and abroad (Graff Zivin and Neidell, 2014), this paper incorporates the wage growth in each industry with 1 lag into the dynamic panel estimation model.

\subsection{Variable selection and data source}

\subsubsection{Variable definition and correction}

\section{(1) Key variables}

a. The net increase of the average wage(Wag): To examine the effect of rising temperature on wage growth, this paper takes the net increase of the average wage in the sample area in the current year as the explanatory variable instead of considering the average wage as the explanatory variable by previous scholars. In addition, due to different natures of work between industries, the agriculture and construction industries in China are generally regarded as highintensity industries at this stage, and their workplaces are usually outdoors. In contrast, the manufacturing and finance industries are relatively less intensive and work mainly indoors. Therefore, with reference to existing studies (Orlov et al., 2020), this paper selects agriculture ${ }^{4}$, manufacturing, construction and finance industries to examine the heterogeneous effects of temperature rise on wages in different industries in order to have a comprehensive and accurate understanding;

b. Temperature(Tem): Most of the extant studies on the impact of temperature rise on the economy, especially on labor productivity, have considered only a single element, temperature, and taken the absolute value of average temperature as an explanatory variable. However, since the body temperature of workers depends on both external temperature and relative humidity at the same time, the above approach of measuring temperature fluctuations by considering only the temperature ignores the amplifying effect on human heat stress caused by warm and humid climatic conditions and by high humidity under continuous hot conditions. More importantly, the spatial distribution of temperature and precipitation varies greatly across the vast territory of China, which causes unsimilar sensitivities of workers to temperatures in different regions. In view of this, based on existing studies (Russo et al., 2017; Willett and Sherwood, 2012), this paper examines the effect of temperature increase on wages using the WBGT index, which is composed of three elements: natural wet-bulb temperature, black-bulb temperature, and dry-bulb temperature, taking into account the heat absorbed from solar radiation and evaporative heat dissipation associated with air humidity (Lee and Min, 2018; Budd, 2008). Integrating the availability of data, this paper adopts commonly used WBGT index to calculate heat stress under average outdoor daytime

4 Agriculture in this paper refers to agriculture in a broad sense, including industries such as farming, forestry, animal husbandry and fishing. 
conditions (Knutson and Ploshay, 2016), with the following equation:

$$
\begin{gathered}
W B G T=0567 \times T_{a}+394+0393 \times E \\
E=6.1121 \times 1.0007+(0.00000346 \times P) \\
\times E X P\left(\left(\left(18.729-\left(T_{a} / 227.3\right)\right) T_{a}\right) /\left(257.87+T_{a}\right)\right)
\end{gathered}
$$

where $T_{a}$ denotes the dry-bulb temperature (in ${ }^{\circ} \mathrm{C}$ ), $E$ is the water vapor pressure (in $\mathrm{hPa}$ ), and the constant 3.94 indicates the effect of heat from solar radiation on WBGT in calm outdoor work. The water vapor pressure is calculated according to Equ.10, where $P$ is the air pressure (in $\mathrm{hPa}$ ).

In addition, existing studies show the complexity and diversity of climate change, rather than being a simple temperature increase (Chen et al., 2019). The occurrence of high summer temperatures and winter frosts in the same region is common in the country. If the absolute value of annual mean temperature changes is included in the analysis, it may mask the temperature fluctuations between seasons and regions, which will most likely lead to biased estimation results. Therefore, this paper uses the historical average WBGT values of the sample regions as a reference for calibration ${ }^{5}$, and further examines the impact of rising temperatures in summer (May-October) on wage growth (Hsiang et al., 2017) ${ }^{6}$.

(2) Control variables

a. Consumer Price Index (Cpi). This variable measures changes in the prices of commodities and labor related to residents' lives, and is usually used as an important indicator to observe inflation level. If CPI keeps growing, the purchasing power of residents' wages will keep decreasing, so will their real wages;

b. Minimum wage standard(Mws). The fundamental purpose of minimum wage policies is to protect the basic livelihood of individual workers and their families, and to promote social equity and stability. Thus, this variable often has an important impact on low-wage groups. This paper uses the logarithm of the annual minimum wage to represent it;

c. Per capita dependents among total employed population(Pcd). This variable is an important indicator to measure social security in cities, and often the higher the value, the higher the wages. In this paper, it is expressed with the logarithm of the ratio of the total urban population to the employed population.

5 This paper defines the temperature change in period $j$ in area $i$ as: $\Delta T_{i j}=T_{i j}-T_{i} . T_{i j}$ is the average temperature of area $i$ during the $j$ period. The reference temperature level of $i$ of area $T_{i}$ is expressed by the average temperature of the area during the 23 years from 1973 to 1995. In addition, through a review of the relevant literature under the reference temperature, it is found that the time span of the reference temperature is different in the existing researches. Most scholars have focused on the 15-30-year time span to describe the reference temperature level of area $i$. Therefore, this article, while referring to the existing literature and being confined to the availability of data, selects the region's 23-year average temperature to represent its reference temperature level.

6 Due to China's vast territory and complex geographical conditions, the climate varies greatly from place to place, with varied lengths of the four seasons. This paper summarizes the beginning and end of summer in various parts of China and defines summer's span as from May to October. 
Table 2 Descriptive analysis results

\begin{tabular}{|c|c|c|c|c|}
\hline Variables & Mean. & S.D. & Min. & Max. \\
\hline Average annual temperature & 0.543 & 0.443 & -1.201 & 2.894 \\
\hline Average summer temperature & 0.537 & 0.571 & -0.819 & 3.996 \\
\hline $\begin{array}{c}\text { The net increase of the average wage } \\
\text { in agriculture }\end{array}$ & 9.442 & 0.707 & 7.918 & 11.077 \\
\hline $\begin{array}{l}\text { The net increase of the average wage } \\
\text { in manufacturing }\end{array}$ & 9.726 & 0.724 & 8.101 & 12.355 \\
\hline $\begin{array}{l}\text { The net increase of the average } \\
\text { wage in construction }\end{array}$ & 9.693 & 0.676 & 8.217 & 11.100 \\
\hline $\begin{array}{l}\text { The net increase of the average } \\
\text { wage in financial }\end{array}$ & 10.288 & 0.912 & 7.662 & 12.14 \\
\hline Consumer price index & 4.763 & 0.156 & 4.471 & 5.185 \\
\hline Minimum wage standard & 6.432 & 0.717 & 4.787 & 7.792 \\
\hline $\begin{array}{l}\text { Per capita dependents among total } \\
\text { employed population }\end{array}$ & 1.559 & 0.554 & 0.209 & 2.724 \\
\hline $\begin{array}{l}\text { Dummy variables for regions with high } \\
\text { average annual temperature fluctuations }\end{array}$ & 0.426 & 0.495 & 0 & 1 \\
\hline $\begin{array}{l}\text { Dummy variables for regions with high } \\
\text { average summer temperature fluctuations }\end{array}$ & 0.381 & 0.486 & 0 & 1 \\
\hline $\begin{array}{l}\text { Dummy variable for relatively vulnerable } \\
\text { regions for wage in agriculture }\end{array}$ & 0.504 & 0.500 & 0 & 1 \\
\hline $\begin{array}{l}\text { Dummy variable for relatively vulnerable } \\
\text { regions for wage in manufacturing }\end{array}$ & 0.464 & 0.499 & 0 & 1 \\
\hline $\begin{array}{l}\text { Dummy variable for relatively vulnerable } \\
\text { regions for wage in construction }\end{array}$ & 0.519 & 0.500 & 0 & 1 \\
\hline $\begin{array}{l}\text { Dummy variable for relatively vulnerable } \\
\text { regions for wage in financial }\end{array}$ & 0.538 & 0.499 & 0 & 1 \\
\hline
\end{tabular}

\subsubsection{Data sources}

The data used in this paper covers 30 provincial capitals. With reference to existing studies, and due to the limited availability of data, the sample data in this paper were selected for the period of 1996-2018. The data of temperature and air pressure in each region were obtained from the Dataset of Annual Values of Climate Data from Chinese Surface Stations. This paper first collates the daily data for each $0.75^{\circ} \times 0.75^{\circ}$ weather variable within China, and then matches the network weather variable data to the prefecture-level cities according to the latitude and longitude. The variables such as wage level, CPI, total urban population, and employed population by region were mainly obtained from the official information opened to the public, including the China Statistical Yearbook and provincial and municipal statistical yearbooks. Income indicators, such as wage level and minimum wage standard in each region, are deflated using the Cpi. At the same time, in order to eliminate the dimension of different variables and to avoid heteroskedasticity, the data of the variables involved in the model are logarithmically processed. The missing data are supplemented by interpolation. The descriptive statistics of the required variables in this paper are shown in Table.2. 


\section{Empirical results and analysis}

\subsection{Baseline regression analysis}

Table. 3 shows the impact of annual average temperature increase on the growth of wage in each industry. The estimation results show that the increase in average temperature will limit the growth rate of wages of workers in agriculture, manufacturing and finance industries. Wage growth in manufacturing is more sensitive to the negative impact of temperature increase than in other industries. This may be due to the fact that most manufacturing industries in China are labor-intensive, and therefore, in order to cope with the decrease in labor productivity and the increase in production costs due to the rise in temperature, labor-intensive manufacturing firms tend to reduce labor inputs, substitute factors, or choose to shift production to other regions in China to ensure maximus profits. Therefore, the negative impact of rising annual average temperature on wage growth in China's manufacturing industry is greater.

In addition, this paper further introduces the interaction term between temperature rises and relatively vulnerable regions and regions with high temperature fluctuations to explore the heterogeneous effects of temperature rise on wage growth. The results show that the negative impact of temperature rise on the growth of wages in each industry is more obvious after the introduction of the interaction term. Among them, the coefficient of the interaction term is significantly negative in relatively vulnerable regions, indicating that the negative impact of rising temperature on wage growth in all industries is greater in relatively vulnerable regions. This finding is generally consistent with the findings of existing studies (Kumar and Khanna, 2019), that the negative impact of temperature rise is "pro-poor". On the one hand, the probability of being exposed to the risk of temperature rise is not the same among income groups due to differences in socioeconomic situations (Coneus and Spiess, 2012). Lowincome groups are more likely to engage in productive activities with higher exposure, and thus they face higher exposure to temperature rise, which makes them more sensitive to its negative impacts; on the other hand, low-income groups are relatively less able to adapt to temperature rises due to their limited material and human capital. For example, for high-income groups, purchasing air conditioners is an effective adaptation strategy to cope with high temperatures, which can avoid or significantly reduce harmful substances in the indoor environment, while the spread of mechanization can reduce the work intensity and thus the economic costs generated by the health system (Bond et al., 2010). Low-income groups, on the other hand, have difficulties in bearing the costs of air conditioning and mechanization. Therefore, the growth of wages across industries in relatively vulnerable regions is more negatively impacted by the rise in temperature.

As temperature rises, the marginal damage brought by it to different industries begins to show significant differences. In particular, the coefficient of the interaction term between the temperature rise in the financial industry and the regions with high temperature fluctuations is significantly negative, 
Table 3 Estimated results of the impact of rising average annual temperatures on wage growth

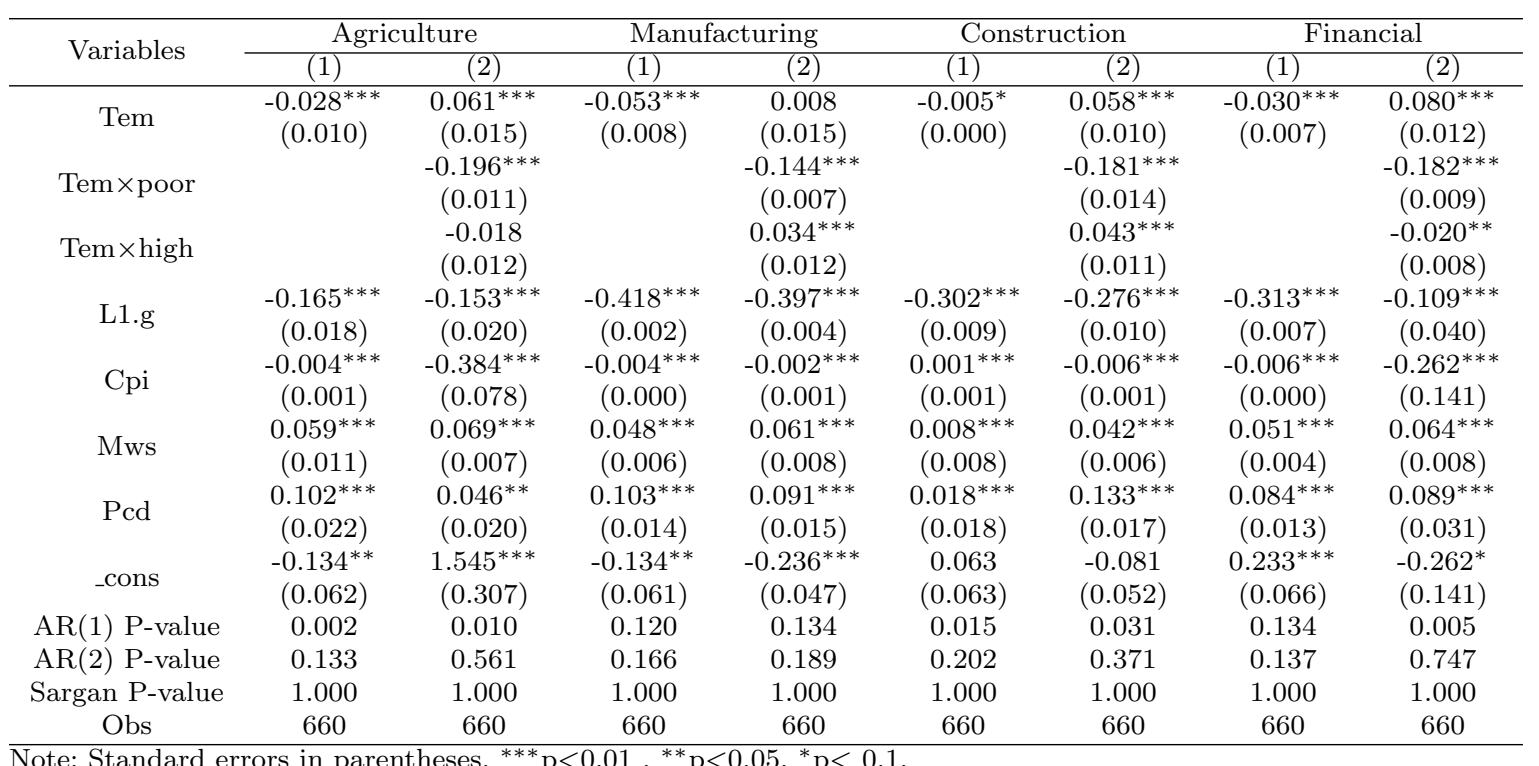

indicating that the marginal damage of temperature rise on wages usually tends to increase gradually as temperature increases. For manufacturing and construction, the coefficient of the interaction term between temperature rises and the regions with high temperature fluctuations is significantly positive, which indicates that for the two sectors, regions with relatively mild temperature fluctuations are more negatively affected by the increase in annual average temperature. For agriculture, the effect of temperature fluctuation on wage growth is not significant. It can be seen that for these industries, plus the manufacturing and the construction industries, the above findings are contrary to the previous theoretical inferences and perceptions, which may be explained by the fact that the impact of the increase in annual average temperature is not always negative due to the combination of both climate change diversity and the seasonality of production in the agriculture industries (Wilkinson and Audsley, 2013).

\subsection{Further analysis}

\subsubsection{Analysis of the impact of rising average summer temperatures on wage} growth

Due to the complexity and diversity of climate change, the increase in annual average temperature may mask the temperature change between seasons and thus obscure its impact on wage growth. Since summer is the time when labor 
productivity is most affected by high temperatures, this paper further examines the impact of rising average summer temperatures on wage growth in the context of global warming in order to provide a more targeted reference for policies on climate change management.

Table.4 shows the estimation results of the impact of summer temperature increase on the growth of wage. According to the regression results, the estimation results of summer temperature increase and annual average temperature increase are basically the same, that is, summer temperature increase will significantly reduce wage growth in each industry. Due to intensified global warming in recent years, extreme summer heat events tend to be frequent across the country. When the WBGT temperature exceeds $30^{\circ} \mathrm{C}$, work ability will be reduced and serious health problems, such as heat stroke, muscle cramps, and even death, may occur (Sadiq et al., 2019). Moderate or very hot conditions may cause a $3 \%-12 \%$ reduction in work time of indoor workers (Xia et al., 2018). The loss of labor efficiency and work time will both have a direct negative impact on the growth of workers' wages. In particular, the manufacturing and financial sectors are more sensitive. In the case of the financial sector, though by intuitive judgement, outdoor workers who are engaged in physical work are more vulnerable to rising temperatures, ergonomic studies have shown that brain-intensive work suffers more disruptions from high temperatures than simple physical labor (Zander and Mathew, 2019). Such brain-intensive and complex labor is more likely to be seen in the financial sector. Wage growth in this sector is, therefore, more sensitive to rising average summer temperatures.

In terms of the heterogeneous effect of rising average summer temperatures on wage growth, the coefficient of the interaction term between relatively vulnerable regions and rising summer temperatures is significantly negative, suggesting that wage growth across industries in these areas is more negatively affected by rising summer temperatures. Although this finding is consistent with the previous inference, it presents significant differences among different industries. In the case of agriculture and manufacturing, the negative impact of temperature rise is more prominent in relatively backward areas, while it seems to be slightly lower in vulnerable regions in construction and finance. However, for different degrees of temperature fluctuations, the coefficient of the interaction term between high temperature fluctuations and temperature increase is significantly negative, indicating that the negative impact of temperature increase on labor productivity and work hours will be further magnified with the increase of temperature fluctuations, i.e., the negative impact of temperature increase on wage growth is greater in regions with relatively higher temperature fluctuations. In addition, the results of the above study confirm the rationality and scientific validity of this paper for using the average temperature in summer, which has more concentrated hot days. 
Table 4 Estimates of the impact of rising summer temperatures on the heterogeneity of wage growth

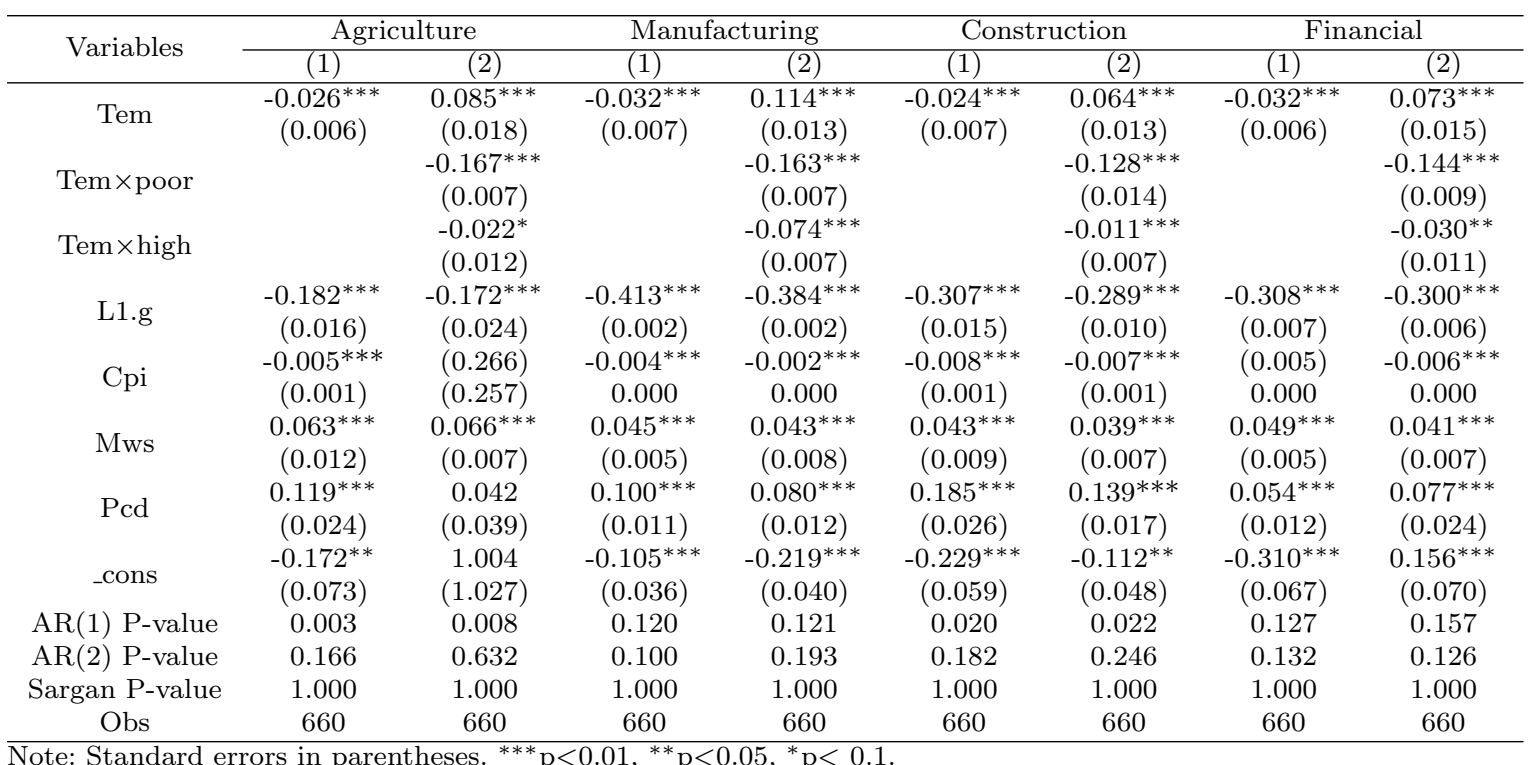

\subsubsection{The cumulative effects of rising temperatures on wage growth - based on long-term temperature changes}

To further examine the cumulative effect of temperature rises, following the practices of Dell et al. (2012) and Chen and Yang (2019), this section includes the degree of temperature rise with 5 lags into the regression model. According to Table.5, the coefficient of the cumulative effect of temperature rise is significantly negative when only 1 lag is considered for the manufacturing and financial sectors, while it is not significant when other lags are introduced. This indicates that for the two sectors, the current period's temperature increase only affects the next period's wages, but has no significant effect on the multi-period lags. In the case of the construction sector, the cumulative effects of temperature rise are not significant, which means that the negative effect of temperature rise exists only in the current period and there is only a horizontal effect of temperature rise on wage growth in the construction industry, which will be reversed when the negative effect of temperature rise disappears. This finding is generally consistent with that of Deryugina and Hsiang (2014), which suggests that the mechanism by which the temperature rise affects wage growth in the construction industry does not include, for example, capital intertemporal investment or inventory decisions. This shows that there is no persistent cumulative effect of rising temperatures on wage growth in the construction industry.

Unlike other industries, although the lag coefficients of agriculture are staggered, the coefficient of cumulative effect of temperature rise in each lag pe- 
Table 5 Estimates of the long-term effects of rising average annual temperatures on wage growth

\begin{tabular}{|c|c|c|c|c|c|c|c|c|}
\hline \multirow{2}{*}{ Variables } & Current period & L.1 period & L.3 period & L.5 period & Current period & L.1 period & L.3 period & L.5 period \\
\hline & \multicolumn{4}{|c|}{ Agriculture } & \multicolumn{4}{|c|}{ Manufacturing } \\
\hline Tem & $\begin{array}{c}-0.028^{* * *} \\
(0.010)\end{array}$ & $\begin{array}{c}-0.028^{* * *} \\
(0.010)\end{array}$ & $\begin{array}{c}-0.023^{*} \\
(0.014)\end{array}$ & $\begin{array}{c}-0.029^{*} \\
(0.018)\end{array}$ & $\begin{array}{c}-0.045^{* * *} \\
(0.007)\end{array}$ & $\begin{array}{c}-0.055^{* * *} \\
(0.010)\end{array}$ & $\begin{array}{c}-0.053^{* * *} \\
(0.012)\end{array}$ & $\begin{array}{c}-0.031^{* *} \\
(0.013)\end{array}$ \\
\hline L1.Tem & & $\begin{array}{c}-0.025^{*} \\
(0.014)\end{array}$ & $\begin{array}{c}-0.038^{* *} \\
(0.015)\end{array}$ & $\begin{array}{l}-0.023 \\
(0.015)\end{array}$ & & $\begin{array}{c}0.029^{* * *} \\
(0.008)\end{array}$ & $\begin{array}{c}0.039^{* * *} \\
(0.010)\end{array}$ & $\begin{array}{c}0.028^{* *} \\
(0.011)\end{array}$ \\
\hline L2.Tem & & & $\begin{array}{c}0.011 \\
(0.013)\end{array}$ & $\begin{array}{l}-0.005 \\
(0.013)\end{array}$ & & & $\begin{array}{c}0.059^{* * *} \\
(0.012)\end{array}$ & $\begin{array}{l}0.021^{*} \\
(0.011)\end{array}$ \\
\hline L3.Tem & & & $\begin{array}{c}-0.036^{* *} \\
(0.016)\end{array}$ & $\begin{array}{c}-0.046^{* * *} \\
(0.013)\end{array}$ & & & $\begin{array}{c}-0.033^{* * *} \\
(0.010)\end{array}$ & $\begin{array}{c}-0.024^{* * *} \\
(0.009)\end{array}$ \\
\hline L4.Tem & & & & $\begin{array}{l}0.020^{*} \\
(0.012)\end{array}$ & & & & $\begin{array}{c}-0.025^{* * *} \\
(0.007)\end{array}$ \\
\hline L5.Tem & & & & $\begin{array}{l}-0.022^{*} \\
(0.012)\end{array}$ & & & & $\begin{array}{c}0.069^{* * *} \\
(0.011)\end{array}$ \\
\hline Cumulative effect & $\begin{array}{c}-0.028^{* * *} \\
(0.010)\end{array}$ & $\begin{array}{c}-0.053^{* * *} \\
(0.020)\end{array}$ & $\begin{array}{c}-0.086^{* * *} \\
(0.036)\end{array}$ & $\begin{array}{c}-0.105^{* * *} \\
(0.034)\end{array}$ & $\begin{array}{c}-0.045^{* * *} \\
(0.007)\end{array}$ & $\begin{array}{c}-0.026^{* *} \\
(0.012)\end{array}$ & $\begin{array}{c}0.013 \\
(0.021)\end{array}$ & $\begin{array}{c}0.038 \\
(0.027)\end{array}$ \\
\hline L1.g & $\begin{array}{c}-0.165^{* * *} \\
(0.018)\end{array}$ & $\begin{array}{c}-0.156^{* * *} \\
(0.014)\end{array}$ & $\begin{array}{c}-0.133^{* * *} \\
(0.022)\end{array}$ & $\begin{array}{c}-0.096^{* * *} \\
(0.019)\end{array}$ & $\begin{array}{c}-0.412^{* * *} \\
(0.002)\end{array}$ & $\begin{array}{c}-0.411^{* * *} \\
(0.003)\end{array}$ & $\begin{array}{c}-0.410^{* * *} \\
(0.004)\end{array}$ & $\begin{array}{c}-0.433^{* * *} \\
(0.003)\end{array}$ \\
\hline _cons & $-0.134^{* *}$ & $-0.179^{* *}$ & $-0.336^{* * *}$ & 0.009 & $-0.130^{* * *}$ & $-0.146^{* *}$ & $-0.460^{* * *}$ & $-0.259^{* *}$ \\
\hline _cons & $(0.062)$ & $(0.100)$ & $(0.130)$ & $(0.104)$ & $(0.040)$ & $(0.063)$ & $(0.126)$ & $(0.119)$ \\
\hline Controlled variables & $\mathrm{Y}$ & $\mathrm{Y}$ & $\mathrm{Y}$ & $\mathrm{Y}$ & $\mathrm{Y}$ & $\mathrm{Y}$ & $\mathrm{Y}$ & $\mathrm{Y}$ \\
\hline $\mathrm{AR}(1) \mathrm{P}$-value & 0.002 & 0.002 & 0.005 & 0.006 & 0.121 & 0.117 & 0.121 & 0.207 \\
\hline $\mathrm{AR}(2) \mathrm{P}$-value & 0.133 & 0.139 & 0.215 & 0.809 & 0.195 & 0.100 & 0.116 & 0.113 \\
\hline Sargan P-value & 1.000 & 1.000 & 1.000 & 1.000 & 1.000 & 1.000 & 1.000 & 1.000 \\
\hline \multirow[t]{2}{*}{ Obs } & 660 & 660 & 600 & 540 & 660 & 660 & 600 & 540 \\
\hline & \multicolumn{4}{|c|}{ Construction } & \multicolumn{4}{|c|}{ Financial } \\
\hline Tem & $\begin{array}{l}-0.307^{*} \\
(0.010)\end{array}$ & $\begin{array}{c}-0.006 \\
(0.034)\end{array}$ & $\begin{array}{l}-0.012 \\
(0.013)\end{array}$ & $\begin{array}{c}-0.016^{* *} \\
(0.009)\end{array}$ & $\begin{array}{c}-0.030^{* * *} \\
(0.007)\end{array}$ & $\begin{array}{c}-0.022^{* *} \\
(0.011)\end{array}$ & $\begin{array}{l}-0.014 \\
(0.014)\end{array}$ & $\begin{array}{c}-0.045^{* * *} \\
(0.017)\end{array}$ \\
\hline L1.Tem & & $\begin{array}{c}0.041 \\
(0.030)\end{array}$ & $\begin{array}{c}0.049^{* * *} \\
(0.008)\end{array}$ & $\begin{array}{c}0.034^{* * *} \\
(0.011)\end{array}$ & & $\begin{array}{c}0.007 \\
(0.010)\end{array}$ & $\begin{array}{c}0.029^{* * *} \\
(0.010)\end{array}$ & $\begin{array}{c}0.00 \\
(0.018)\end{array}$ \\
\hline L2.Tem & & & $\begin{array}{c}0.011 \\
(0.010)\end{array}$ & $\begin{array}{l}-0.005 \\
(0.011)\end{array}$ & & & $\begin{array}{c}0.013 \\
(0.010)\end{array}$ & $\begin{array}{c}0.017 \\
(0.014)\end{array}$ \\
\hline L3.Tem & & & $\begin{array}{l}-0.009 \\
(0.011)\end{array}$ & $\begin{array}{l}-0.009 \\
(0.011)\end{array}$ & & & $\begin{array}{c}0.002 \\
(0.012)\end{array}$ & $\begin{array}{l}-0.001 \\
(0.011)\end{array}$ \\
\hline L4.Tem & & & & $\begin{array}{l}-0.009 \\
(0.011)\end{array}$ & & & & $\begin{array}{l}-0.013 \\
(0.016)\end{array}$ \\
\hline L5.Tem & & & & $\begin{array}{c}0.030^{* * *} \\
(0.010)\end{array}$ & & & & $\begin{array}{l}-0.003 \\
(0.009)\end{array}$ \\
\hline Cumulative effect & $\begin{array}{c}-0.307^{*} \\
(0.010)\end{array}$ & $\begin{array}{c}0.035 \\
(0.050)\end{array}$ & $\begin{array}{c}0.040 \\
(0.029)\end{array}$ & $\begin{array}{c}0.024 \\
(0.029)\end{array}$ & $\begin{array}{c}-0.030^{* * *} \\
(0.007)\end{array}$ & $\begin{array}{c}-0.014^{* * *} \\
(0.018)\end{array}$ & $\begin{array}{c}0.030 \\
(0.023)\end{array}$ & $\begin{array}{l}-0.041 \\
(0.036)\end{array}$ \\
\hline L1.g & $\begin{array}{c}-0.307^{* * *} \\
(0.010)\end{array}$ & $\begin{array}{c}-0.306^{* * *} \\
(0.054)\end{array}$ & $\begin{array}{c}-0.341^{* * *} \\
(0.014)\end{array}$ & $\begin{array}{c}-0.295^{* * *} \\
(0.017)\end{array}$ & $\begin{array}{c}-0.313^{* * *} \\
(0.007)\end{array}$ & $\begin{array}{c}-0.316^{* * *} \\
(0.008)\end{array}$ & $\begin{array}{c}-0.306^{* * *} \\
(0.008)\end{array}$ & $\begin{array}{c}-0.320^{* * *} \\
(0.016)\end{array}$ \\
\hline _cons & $\begin{array}{c}-0.117^{*} \\
(0.060)\end{array}$ & $\begin{array}{l}-0.032 \\
(0.181)\end{array}$ & $\begin{array}{l}-0.200 \\
(0.150)\end{array}$ & $\begin{array}{l}-0.045 \\
(0.104)\end{array}$ & $\begin{array}{c}0.233^{* * *} \\
(0.066)\end{array}$ & $\begin{array}{c}0.281^{* * *} \\
(0.093)\end{array}$ & $\begin{array}{c}0.055 \\
(0.125)\end{array}$ & $\begin{array}{l}0.317^{*} \\
(0.186)\end{array}$ \\
\hline Controlled variables & $\mathrm{Y}$ & $\mathrm{Y}$ & $\mathrm{Y}$ & $\mathrm{Y}$ & $\mathrm{Y}$ & $\mathrm{Y}$ & $\mathrm{Y}$ & $\mathrm{Y}$ \\
\hline $\mathrm{AR}(1) \mathrm{P}$-value & 0.015 & 0.024 & 0.046 & 0.011 & 0.134 & 0.138 & 0.140 & 0.215 \\
\hline $\mathrm{AR}(2) \mathrm{P}$-value & 0.202 & 0.197 & 0.113 & 0.244 & 0.137 & 0.137 & 0.135 & 0.158 \\
\hline Sargan P-value & 1.000 & 1.000 & 1.000 & 1.000 & 1.000 & 1.000 & 1.000 & 1.000 \\
\hline Obs & 660 & 660 & 600 & 540 & 660 & 660 & 600 & 540 \\
\hline
\end{tabular}


riod is still significantly negative, and the cumulative effect of temperature rise gradually increases with the increase of the number of lag periods in the regression equation. This indicates that the negative impact of temperature rises on the growth of wage in agriculture will persist for a long time, and the temperature rise will not only affect the growth of wage in the current period, but also through the lagged effect. This may be due to the fact that temperature increase not only affects workers in these industries, but also directly affects their production (Roberts and Schlenker, 2013), both of which will directly affect the wage growth in these sectors. Take crops as an example, the rise in temperatures may increase the probability of occurrence and spread of pests and diseases, shorten the fertility period, and lead to a decrease in yield. In this case, producers, as rational economic men, will inevitably reduce the input of each factor of production so as to maximize profits. When labor supply remains unchanged, the decrease of labor hire demand will directly affect the labor hire price, resulting in a decrease in wages, which will have a lagged level effect. When the capital stock adjusts to a new steady state, the permanent shock to productivity from this effect may in turn affect subsequent capital accumulation, producing a lagged growth effect. As can be seen, there is not only a level effect but also a growth effect of the negative effect of rising temperatures, both of which may have an impact on the growth of wages in agriculture. The difference is, when the temperature returns to normal, the labor input time can return to normal, i.e., the level effect on wages will be reversed. In contrast, however, the lagged growth effect on workers' productivity is not reversed by reduced temperatures, and the existence of the effect means that an increase in temperature rise in a period may lead to a prolonged low wage level.

\subsection{Robustness tests}

\subsubsection{Recalculation of temperature rise indicators}

To avoid biased estimation results due to indicator accounting, this paper refers to the approach adopted by Zhang et al. (2018), by dividing temperature intervals based on daily average temperature values. Taking the number of days in a year when temperature values fall into each interval as the measurement variable, it constructs the following model for estimation:

$$
g_{i t}=\alpha^{m} \text { Tbin }_{i t}^{m}+\lambda \text { control }_{i t}+\eta_{i}+\sigma_{t}+\varepsilon_{i t}
$$

where $\operatorname{Tbin}_{i t}^{m}$ denotes the total number of days that the daily average temperature of region $i$ falls into the $m$ temperature interval in year $t$. In this paper, the daily average temperature values are divided into 9 temperature intervals with a length of $6^{\circ} \mathrm{C}$. They are: less than $-12^{\circ} \mathrm{C},-12-6^{\circ} \mathrm{C},-6-0^{\circ} \mathrm{C}, 0-6^{\circ} \mathrm{C}, 6-12^{\circ} \mathrm{C}$, $12-18^{\circ} \mathrm{C}, 18-24^{\circ} \mathrm{C}, 24-30^{\circ} \mathrm{C}$, and greater than $30^{\circ} \mathrm{C}$. To avoid multicollinearity, referring to Chen and Yang (2019), this paper selects the temperature interval $18-24^{\circ} \mathrm{C}$ as the reference group. $\eta_{i}$ denotes area fixed effects, $\sigma_{i}$ denotes year 
Table 6 Robustness tests: reaccounting for temperature indicators

\begin{tabular}{|c|c|c|c|c|c|c|}
\hline & \multicolumn{3}{|c|}{ Agriculture } & \multicolumn{3}{|c|}{ Manufacturing } \\
\hline & (1) & $(2)$ & $(3)$ & (1) & $(2)$ & $(3)$ \\
\hline \multirow{2}{*}{$<-12^{\circ} \mathrm{C}$} & $-0.023^{*}$ & $-0.028^{*}$ & $-0.059^{* *}$ & $-0.002^{*}$ & $-0.014^{*}$ & -0.004 \\
\hline & $(0.013)$ & $(0.016)$ & $(0.006)$ & $(0.001)$ & $(0.008)$ & $(0.021)$ \\
\hline \multirow{2}{*}{$-12--6^{\circ} \mathrm{C}$} & -0.001 & 0.001 & -0.002 & 0.001 & 0.004 & -0.002 \\
\hline & $(0.001)$ & $(0.002)$ & $(0.001)$ & $(0.001)$ & $(0.006)$ & $(0.005)$ \\
\hline \multirow{2}{*}{$-6-0^{\circ} \mathrm{C}$} & $-0.005^{* *}$ & $-0.006^{* *}$ & $-0.004^{* *}$ & 0.000 & 0.000 & -0.001 \\
\hline & $(0.002)$ & $(0.003)$ & $(0.002)$ & $(0.002)$ & $(0.003)$ & $(0.004)$ \\
\hline \multirow{2}{*}{$0-6^{\circ} \mathrm{C}$} & -0.001 & 0.000 & -0.002 & 0.001 & 0.001 & 0.001 \\
\hline & $(0.001)$ & $(0.002)$ & $(0.001)$ & $(0.001)$ & $(0.002)$ & $(0.003)$ \\
\hline \multirow{2}{*}{$12-18^{\circ} \mathrm{C}$} & 0.000 & 0.001 & -0.001 & 0.001 & 0.001 & 0.002 \\
\hline & $(0.001)$ & $(0.002)$ & $(0.001)$ & $(0.001)$ & $(0.002)$ & $(0.002)$ \\
\hline \multirow{2}{*}{$18-24^{\circ} \mathrm{C}$} & 0.000 & 0.001 & -0.001 & 0.001 & 0.002 & 0.000 \\
\hline & $(0.001)$ & $(0.002)$ & $(0.001)$ & $(0.001)$ & $(0.003)$ & $(0.002)$ \\
\hline \multirow{2}{*}{$24-30^{\circ} \mathrm{C}$} & -0.0007 & 0.0004 & $-0.002^{*}$ & 0.000 & -0.000 & -0.001 \\
\hline & $(0.001)$ & $(0.001)$ & $(0.001)$ & $(0.001)$ & $(0.002)$ & $(0.001)$ \\
\hline \multirow{2}{*}{$>30^{\circ} \mathrm{C}$} & $-0.001^{*}$ & 0.000 & $-0.003^{*}$ & $-0.001^{* *}$ & 0.002 & $-0.003^{*}$ \\
\hline & $(0.000)$ & $(0.001)$ & $(0.001)$ & $(0.001)$ & $(0.002)$ & $(0.001)$ \\
\hline Obs & 690 & 318 & 372 & 690 & 318 & 372 \\
\hline$R^{2}$ & 0.065 & 0.162 & 0.125 & 0.029 & 0.123 & 0.107 \\
\hline Controlled variable & $\mathrm{Y}$ & $\mathrm{Y}$ & $\mathrm{Y}$ & $\mathrm{Y}$ & $\mathrm{Y}$ & $\mathrm{Y}$ \\
\hline Regional fixed effects & $\mathrm{Y}$ & $\mathrm{Y}$ & $\mathrm{Y}$ & $\mathrm{Y}$ & $\mathrm{Y}$ & $\mathrm{Y}$ \\
\hline \multirow[t]{2}{*}{ Year fixed effects } & $\mathrm{Y}$ & $\mathrm{Y}$ & $\mathrm{Y}$ & $\mathrm{Y}$ & $\mathrm{Y}$ & $\mathrm{Y}$ \\
\hline & \multicolumn{3}{|c|}{ Construction } & \multicolumn{3}{|c|}{ Financial } \\
\hline \multirow{2}{*}{$<-12^{\circ} \mathrm{C}$} & $-0.003^{*}$ & -0.012 & -0.000 & -0.005 & -0.012 & $-0.035^{* *}$ \\
\hline & $(0.002)$ & $(0.007)$ & $(0.020)$ & $(0.009)$ & $(0.011)$ & $(0.016)$ \\
\hline \multirow{2}{*}{$-12--6^{\circ} \mathrm{C}$} & -0.000 & 0.004 & -0.003 & -0.000 & 0.003 & -0.002 \\
\hline & $(0.001)$ & $(0.006)$ & $(0.004)$ & $(0.001)$ & $(0.003)$ & $(0.002)$ \\
\hline \multirow{2}{*}{$-6-0^{\circ} \mathrm{C}$} & -0.001 & 0.000 & -0.003 & -0.001 & 0.001 & -0.003 \\
\hline & $(0.002)$ & $(0.003)$ & $(0.004)$ & $(0.001)$ & $(0.002)$ & $(0.002)$ \\
\hline \multirow{2}{*}{$0-6^{\circ} \mathrm{C}$} & 0.001 & 0.002 & -0.001 & -0.000 & 0.002 & -0.000 \\
\hline & $(0.001)$ & $(0.002)$ & $(0.002)$ & $(0.001)$ & $(0.002)$ & $(0.001)$ \\
\hline \multirow{2}{*}{$12-18^{\circ} \mathrm{C}$} & 0.00 & 0.001 & 0.000 & 0.000 & 0.001 & 0.00 \\
\hline & $(0.001)$ & $(0.002)$ & $(0.001)$ & $(0.001)$ & $(0.002)$ & $(0.001)$ \\
\hline \multirow{2}{*}{$18-24^{\circ} \mathrm{C}$} & -0.000 & 0.002 & -0.002 & -0.001 & -0.003 & -0.000 \\
\hline & $(0.001)$ & $(0.003)$ & $(0.001)$ & $(0.001)$ & $(0.003)$ & $(0.001)$ \\
\hline \multirow{2}{*}{$24-30^{\circ} \mathrm{C}$} & -0.000 & -0.000 & -0.001 & -0.001 & 0.002 & -0.001 \\
\hline & $(0.001)$ & $(0.002)$ & $(0.001)$ & $(0.001)$ & $(0.002)$ & $(0.001)$ \\
\hline \multirow{2}{*}{$>30^{\circ} \mathrm{C}$} & $-0.001^{*}$ & 0.001 & $-0.002^{*}$ & $-0.001^{*}$ & -0.001 & $-0.003^{* *}$ \\
\hline & $(0.000)$ & $(0.002)$ & $(0.001)$ & $(0.001)$ & $(0.002)$ & $(0.001)$ \\
\hline Obs & 690 & 318 & 372 & 690 & 318 & 372 \\
\hline$R^{2}$ & 0.039 & 0.163 & 0.119 & 0.052 & 0.198 & 0.136 \\
\hline Controlled variable & $\mathrm{Y}$ & $\mathrm{Y}$ & $\mathrm{Y}$ & $\mathrm{Y}$ & $\mathrm{Y}$ & $\mathrm{Y}$ \\
\hline Regional fixed effects & $\mathrm{Y}$ & $\mathrm{Y}$ & $\mathrm{Y}$ & $\mathrm{Y}$ & $\mathrm{Y}$ & $\mathrm{Y}$ \\
\hline Year fixed effects & $Y$ & $\mathrm{Y}$ & $\mathrm{Y}$ & $\mathrm{Y}$ & $\mathrm{Y}$ & $\mathrm{Y}$ \\
\hline
\end{tabular}

fixed effects, and $\varepsilon_{i t}$ denotes robustness standard errors of clustering to the regional level.

Table. 6 reports the estimation results based on Equ.11, where column (1) shows the regression results based on the full sample. It can be found that the effect of temperature change on wages displays an obvious "inverted U- 
shaped" curve: with $18-24^{\circ} \mathrm{C}$ as the reference range ${ }^{7}$, a decrease or increase in temperature will both result in a negative impact on the growth of wage in each industry. Column (2) shows the regression results for relatively developed regions, and it is found that the effect of temperature below or above $18-24^{\circ} \mathrm{C}$ on wages in relatively developed regions is not significant. This finding is generally consistent with the results of Dell et al. (2012). A widely accepted explanation is that compared to relatively vulnerable regions, relatively developed regions are more willing and able to adopt adaptive measures in response to climate change. Therefore, the negative impacts of climate change are almost negligible. The regression results based on the sample of relatively vulnerable regions are reported in column (3) of Table.6. The results show that, relative to the $18-24^{\circ} \mathrm{C}$ interval, when the temperature rises to $24-30^{\circ} \mathrm{C}$, it has a significant negative effect on the growth of wage in all industries in the relatively vulnerable regions. The absolute values of the estimation coefficient of the temperature interval variables keeps getting large as the temperature rises above $30^{\circ} \mathrm{C}$, indicating that the negative impact on the growth of wages in each industry becomes progressively obvious as the temperature rises. In addition to that, in terms of the heterogeneity across industries, the manufacturing and financial sectors are more negatively affected by rising temperatures when temperatures rise above $30^{\circ} \mathrm{C}$, compared to the $18-24^{\circ} \mathrm{C}$ reference range. The above results confirm the "pro-poor" nature of the climate change impacts, and also prove the robustness of this paper's reference regression results.

\subsubsection{Redefinition of relatively vulnerable regions and regions with high temperature fluctuations}

In the baseline regression, the criteria for distinguishing the relatively vulnerable regions and the regions with high temperature fluctuations is the mean value of the wage of each industry in each city during the sample period, and the mean value of the temperature fluctuation in each city during the sample period, respectively. In order to avoid the interference of the regression results with the sample classification criteria, this paper redefines the relatively vulnerable regions and regions with high temperature fluctuations by using the median of wages and temperature fluctuation values as the criteria, respectively. According to the estimation results in column (1) of Table.7, it can be seen that the baseline conclusion of this paper still holds regardless of the division criterion used.

7 The standard for selecting the temperature reference group is: to try to select different temperature intervals as the reference group for regression analysis. When a certain temperature interval is used as the reference group, the estimated coefficients of the remaining intervals are all significantly negative, then the temperature interval is selected as the final reference group. At the same time, the range of the reference temperature selected in this paper is also similar to those used by Burke et al. (2015), Zhang et al. (2018), among others. 
Table 7 Robustness tests: redefining dummy variables and summer temperature intervals

\begin{tabular}{|c|c|c|c|c|c|c|c|c|}
\hline \multirow{2}{*}{ Variables } & \multicolumn{2}{|c|}{ Agriculture } & \multicolumn{2}{|c|}{ Manufacturing } & \multicolumn{2}{|c|}{ Construction } & \multicolumn{2}{|c|}{ Financial } \\
\hline & $(1)$ & $(2)$ & $(1)$ & $(2)$ & $(1)$ & $(2)$ & $(1)$ & $(2)$ \\
\hline \multirow{2}{*}{ Tem } & $0.083^{* * *}$ & 0.016 & 0.007 & $0.035^{*}$ & $0.077^{* * *}$ & 0.012 & $0.033^{* *}$ & $0.046^{* * *}$ \\
\hline & $(-0.016)$ & $(-0.016)$ & $(-0.016)$ & $(-0.011)$ & $(-0.014)$ & $(-0.011)$ & $(-0.015)$ & $(-0.010)$ \\
\hline \multirow{2}{*}{ Tem $\times$ poor } & $-0.203^{* * *}$ & $-0.122^{* * *}$ & $-0.143^{* * *}$ & $-0.119^{* * *}$ & $-0.183^{* * *}$ & $-0.087^{* * *}$ & $-0.194^{* * *}$ & $-0.123^{* * *}$ \\
\hline & $(-0.010)$ & $(-0.009)$ & $(-0.007)$ & $(-0.005)$ & $(-0.013)$ & $(-0.013)$ & $(-0.008)$ & $(-0.005)$ \\
\hline \multirow{2}{*}{ Tem $\times$ high } & -0.014 & $-0.038^{* * *}$ & $0.035^{* * *}$ & $-0.013^{*}$ & $0.024^{*}$ & $-0.036^{* * *}$ & $-0.052^{* * *}$ & $-0.030^{* * *}$ \\
\hline & $(-0.012)$ & $(-0.014)$ & $(-0.012)$ & $(-0.007)$ & $(-0.014)$ & $(-0.011)$ & $(-0.010)$ & $(-0.008)$ \\
\hline \multirow{2}{*}{ L1.g } & $-0.114^{* * *}$ & $-0.137 * * *$ & $-0.397^{* * *}$ & $-0.395^{* * *}$ & $-0.269^{* * *}$ & $-0.284^{* * *}$ & $-0.303^{* * *}$ & $-0.305^{* * *}$ \\
\hline & $(-0.012)$ & $(-0.01)$ & $(-0.004)$ & $(-0.002)$ & $(-0.011)$ & $(-0.010)$ & $(-0.009)$ & $(-0.007)$ \\
\hline \multirow[b]{2}{*}{ _cons } & $-0.147^{* * *}$ & -0.188 & $-0.217^{* * *}$ & $-0.193^{* * *}$ & $-0.126^{* * *}$ & -0.074 & $0.235^{* * *}$ & $0.211^{* *}$ \\
\hline & $(-0.094)$ & $(-0.125)$ & $(-0.039)$ & $(-0.041)$ & $(-0.047)$ & $(-0.053)$ & $(-0.079)$ & $(-0.096)$ \\
\hline Controlled variables & $\mathrm{Y}$ & $\mathrm{Y}$ & $\mathrm{Y}$ & $\mathrm{Y}$ & $\mathrm{Y}$ & $\mathrm{Y}$ & $\mathrm{Y}$ & $\mathrm{Y}$ \\
\hline AR(1) P-value & 0.000 & 0.135 & 0.157 & 0.151 & 0.031 & 0.000 & 0.027 & 0.107 \\
\hline $\mathrm{AR}(2) \mathrm{P}$-value & 0.162 & 0.179 & 0.146 & 0.168 & 0.133 & 0.145 & 0.149 & 0.151 \\
\hline Sargan P-value & 1.000 & 1.000 & 1.000 & 1.000 & 1.000 & 1.000 & 1.000 & 1.000 \\
\hline Obs & 660 & 660 & 660 & 660 & 660 & 660 & 660 & 660 \\
\hline
\end{tabular}

\subsubsection{Re-selection of the summer temperature interval lengths}

In order to avoid possible interference of the sample interval length with the estimation results, this paper re-selects June, July and August, when the hot weather is more concentrated, as the time intervals to divide the summer season for robustness testing. According to the regression results in column (2) of Table.7, it can be seen that the estimation results of the core variables of interest in this paper are consistent with what previously stated, which again proves that the baseline regression results of this paper are robust.

\subsection{4 "Heat island effect" test}

In the baseline regression, 30 provincial capitals were selected as samples for the analysis, however, these cities are often densely populated, with high emissions of heat from factories and vehicles, and high emissions of energy from residential use, which may have a significant urban "heat island effect". In order to avoid the possible interference of the sample selection with the estimation results, the paper re-estimates the results by selecting 30 provincial capital cities with peri-urban temperature observation data. The regression results in Table. 8 show that for the core variables of interest, the results are consistent with the baseline regression results for provincial capitals, indicating that the increase in annual average temperature in peri-urban areas also has a negative impact on the growth of wage income in all sectors, demonstrating the robustness of the baseline regression results in this paper. 
Table 8 Robustness tests: results of estimating the impact of rising average annual temperatures on wage growth in suburban areas

\begin{tabular}{|c|c|c|c|c|c|c|c|c|}
\hline \multirow{2}{*}{ Variables } & \multicolumn{2}{|c|}{ Agriculture } & \multicolumn{2}{|c|}{ Manufacturing } & \multicolumn{2}{|c|}{ Construction } & \multicolumn{2}{|c|}{ Financial } \\
\hline & $(1)$ & $(2)$ & (1) & $(2)$ & $(1)$ & $(2)$ & (1) & $(2)$ \\
\hline & $-0.001^{*}$ & $0.106^{* * *}$ & $-0.025^{* * *}$ & 0.011 & $-0.021^{* *}$ & $0.140^{* * *}$ & $-0.034^{* * *}$ & $0.166^{* * *}$ \\
\hline Tem & 0.000 & $(0.008)$ & $(0.006)$ & $(0.010)$ & $(0.006)$ & $(0.008)$ & $(0.004)$ & $(0.012)$ \\
\hline & & $-0.192^{* * *}$ & & $-0.169^{* * *}$ & & $-0.179^{* * *}$ & & $-0.196^{* * *}$ \\
\hline 1em $\times$ poor & & $(0.010)$ & & $(0.008)$ & & $(0.006)$ & & $(0.011)$ \\
\hline & & -0.007 & & $0.056^{* * *}$ & & $-0.037^{*}$ & & $-0.038^{* * *}$ \\
\hline Iem × high & & $(0.006)$ & & $(0.007)$ & & $(0.008)$ & & $(0.010)$ \\
\hline & $-0.165^{* * *}$ & $-0.115^{* * *}$ & $-0.413^{* * *}$ & $-0.388^{* * *}$ & $-0.313^{* * *}$ & $-0.267^{* * *}$ & $0.306^{* * *}$ & $-0.285^{* * *}$ \\
\hline Ll.g & $(0.019)$ & $(0.013)$ & $(0.002)$ & $(0.003)$ & $(0.007)$ & $(0.006)$ & $(0.008)$ & $(0.008)$ \\
\hline & $-0.341^{* * *}$ & $1.224^{* * *}$ & -0.098 & $-0.161^{* *}$ & $-0.125^{*}$ & $0.000^{* *}$ & $0.351^{* * *}$ & $0.281^{* * *}$ \\
\hline _cons & $(0.091)$ & $(0.471)$ & $(0.060)$ & $(0.067)$ & $(0.066)$ & $(0.044)$ & $(0.057)$ & $(0.078)$ \\
\hline Controlled variables & $\mathrm{Y}$ & $\mathrm{Y}$ & $\mathrm{Y}$ & $\mathrm{Y}$ & $\mathrm{Y}$ & $\mathrm{Y}$ & $\mathrm{Y}$ & $\mathrm{Y}$ \\
\hline $\mathrm{AR}(1) \mathrm{P}$-value & 0.000 & 0.000 & 0.000 & 0.000 & 0.053 & 0.165 & 0.155 & 0.149 \\
\hline $\mathrm{AR}(2) \mathrm{P}$-value & 0.145 & 0.148 & 0.157 & 0.124 & 0.121 & 0.862 & 0.191 & 0.151 \\
\hline Sargan P-value & 1.000 & 1.000 & 1.000 & 1.000 & 1.000 & 1.000 & 1.000 & 1.000 \\
\hline Obs & 660 & 660 & 660 & 660 & 660 & 660 & 660 & 660 \\
\hline
\end{tabular}

\section{Conclusion and recommendations}

Based on the panel data of 30 provincial capital cities from 1996 to 2018, this paper conducts an empirical study on the effect of rising temperature on wage in different industries. The study found that: Firstly, rising temperature will significantly reduce the growth rate of wage in various industries, showing obvious heterogeneity. Among them, the growth of wage in manufacturing is most affected by the negative impact of the average annual temperature rise. Secondly, the negative impact of rising temperatures on wage growth is mainly concentrated in the summer. Wage growth in the manufacturing and financial industries is more sensitive to the negative impact of rising average summer temperatures. Thirdly, due to the difference between the vulnerability of the main production body and the degree of temperature fluctuations, the marginal impact of temperature rise shows obvious differences. Among them, in terms of vulnerability, wage in relatively vulnerable areas is more affected by rising temperatures. Concerning the degree of temperature fluctuations, the impact of annual average temperature fluctuations on wage growth shows obvious differences among different industries. The marginal damage of annual average temperature fluctuations to the growth of wage in the financial industry tends to increase with the intensification of temperature fluctuations. However, for the manufacturing and construction industries, regions with relatively mild temperature fluctuations will be more negatively affected by the annual average temperature rise. Different from the degree of annual average temperature fluctuations, the marginal damage to wage growth in various industries is higher in regions where the temperature rises relatively sharply in summer. Fourthly, the negative impact of rising temperature has a cumulative effect on wage growth in agriculture. This negative effect mainly comes 
from the impact of rising temperature on labor productivity and is irreversible, which will further widen the wage gap between regions.

Based on the above findings, this paper explores the effect of temperature rise on wages in various industries, and provides a new perspective to understand the impact of climate change on the economy. The findings of the study are important for policies that promote the governance of climate change and alleviate relative poverty.

In terms of climate change mitigation, the concept of green development should be comprehensively implemented and climate change governance should be actively pursued. This study shows that temperature rises will negatively affect the growth of wages in various industries. In this regard, energy conservation, emission reduction, and energy structure optimization should be embraced. A national unified market for carbon emission trading should be developed, so as a mechanism for sustainable development. This way, we may provide Chinese wisdom and solutions for global climate change governance, build a community of shared future for mankind, and promote high-quality development for China and the world.

Considering climate change adaptation, first of all, we should continue to promote the construction of climate-adapted smart cities, develop climate prediction and early warning mechanisms, public health emergency plans, and climate rescue mechanisms. We should develop an early warning system for health risks caused by high temperatures, so as to effectively predict the extent of heat exposure and disaster impacts in a timely manner. Second, we should make the workforce in various industries more adaptive to climate change. According to researches, the growth of wages in different industries shows significant differences by the negative impact of rising temperature. Among them, manufacturing and construction industries are most affected by the negative marginal impact of temperature rises. For this reason, we should enhance their climate resilience. Occupational health standards and differentiated intervention and response strategies for industries and workers with different exposure levels should be improved.Finally, the R\&D and promotion of climate-resilient technologies (such as those for climate-smart agricultural production), smart manufacturing technologies featuring unmanned systems, and smart service technologies, should be introduced. This paper shows that the "pro-poor" nature of the negative impacts of climate change may be attributed to the relatively weak coping capacity of workers in backward areas and their difficulties in implementing climate adaptation strategies. Therefore, while developing and diffusing technologies, we must make them more available and acceptable. By introducing a reasonable technology subsidy policy, we can transfer advanced technologies to backward areas by means of knowledge popularization and technology promotion. This way, we may effectively make workers in these areas more resilient to climate change and we may encourage them to adopt proper adaptive measures to reduce negative impacts, so as to prevent further widening of the income gap between regions and industries. 


\section{Conflict of interest}

The authors declare that they have no known competing financial interests or personal relationships that could have appeared to influence the work reported in this paper.

\section{Ethical approval}

Not applicable

\section{Consent to participate}

Not applicable

\section{Consent to Publish}

Not applicable

\section{Authors Contributions}

All authors contributed to the study conception and design. Material preparation, data collection and analysis were performed by Hanxiao Xu, Bin Yuan and Qiang Gao. The first draft of the manuscript was written by Hanxiao Xu and all authors commented on previous versions of the manuscript. All authors read and approved the final manuscript.

\section{Funding}

This study was supported in part by grants from Social Science Planning Research Project of Shandong" Research on the Stagnation and Breakthrough Path of Relative Poverty Management in Shandong Province after 2020" (Grant No. 20CDCJ21), The key project of plan in research and development of Shandong" Research on the protection and utilization of marine fishery germplasm resources in Shandong Province" (Grant No. 2020RZE29007), The Natural Science Foundation of Shandong" Research on the Long-term Path of Poverty Alleviation in Agricultural Industry from the Perspective of High-Quality De velopment" (Grant No. ZR2020QG045) ,The Fundamental Research Funds for the Central Universities (Grant No.202013011), The China Postdoctoral Science Foundation (Grant No.2019M652486). 


\section{Availability of data and materials}

The datasets generated during and/or analysed during the current study are available from the corresponding author on reasonable request.

\section{References}

Bond, S., Leblebicioğlu, A., Schiantarelli, F., 2010. Capital accumulation and growth: a new look at the empirical evidence. Journal of Applied Econometrics 25, 1073-1099.

Branco, D., Féres, J., 2021. Weather shocks and labor allocation: Evidence from rural brazil. American Journal of Agricultural Economics 103, 1359 1377.

Brysse, K., Oreskes, N., O’Reilly, J., Oppenheimer, M., 2013. Climate change prediction: Erring on the side of least drama? Global environmental change 23, 327-337.

Budd, G.M., 2008. Wet-bulb globe temperature (wbgt) - its history and its limitations. Journal of science and medicine in sport 11, 20-32.

Burke, M., Hsiang, S.M., Miguel, E., 2015. Global non-linear effect of temperature on economic production. Nature 527, 235-239.

Cai, X., Lu, Y., Wang, J., 2018. The impact of temperature on manufacturing worker productivity: Evidence from personnel data. Journal of Comparative Economics 46, 889-905.

Chen, X., Li, N., Liu, J., Zhang, Z., Liu, Y., 2019. Global heat wave hazard considering humidity effects during the 21st century. International journal of environmental research and public health 16, 1513.

Chen, X., Yang, L., 2019. Temperature and industrial output: Firm-level evidence from china. Journal of Environmental Economics and Management 95, 257-274.

Coneus, K., Spiess, C.K., 2012. Pollution exposure and child health: Evidence for infants and toddlers in germany. Journal of Health Economics 31, 180 196.

Dell, M., Jones, B.F., Olken, B.A., 2012. Temperature shocks and economic growth: Evidence from the last half century. American Economic Journal: Macroeconomics 4, 66-95.

Deryugina, T., Hsiang, S.M., 2014. Does the environment still matter? Daily temperature and income in the United States. Technical Report. National Bureau of Economic Research.

Deschênes, O., Greenstone, M., 2007. The economic impacts of climate change: evidence from agricultural output and random fluctuations in weather. American economic review 97, 354-385.

González-Alonso, J., Teller, C., Andersen, S.L., Jensen, F.B., Hyldig, T., Nielsen, B., 1999. Influence of body temperature on the development of fatigue during prolonged exercise in the heat. Journal of applied physiology 86, 1032-1039. 
Graff Zivin, J., Neidell, M., 2014. Temperature and the allocation of time: Implications for climate change. Journal of Labor Economics 32, 1-26.

Heal, G., Park, J., 2013. Feeling the heat: Temperature, physiology \& the wealth of nations. Technical Report. National Bureau of Economic Research.

Hsiang, S., Kopp, R., Jina, A., Rising, J., Delgado, M., Mohan, S., Rasmussen, D., Muir-Wood, R., Wilson, P., Oppenheimer, M., et al., 2017. Estimating economic damage from climate change in the united states. Science 356, $1362-1369$.

Iyigun, M., Nunn, N., Qian, N., 2017. Winter is coming: The long-run effects of climate change on conflict, 1400-1900. Technical Report. National Bureau of Economic Research.

Knutson, T.R., Ploshay, J.J., 2016. Detection of anthropogenic influence on a summertime heat stress index. Climatic Change 138, 25-39.

Kompas, T., Pham, V.H., Che, T.N., 2018. The effects of climate change on gdp by country and the global economic gains from complying with the paris climate accord. Earth's Future 6, 1153-1173.

Krüger, J.J., Neugart, M., 2018. Weather and intertemporal labor supply: Results from german time-use data. Labour 32, 112-140.

Kumar, S., Khanna, M., 2019. Temperature and production efficiency growth: empirical evidence. Climatic Change 156, 209-229.

Lee, S.M., Min, S.K., 2018. Heat stress changes over east asia under 1.5 and 2.0 c global warming targets. Journal of Climate 31, 2819-2831.

Letta, M., Montalbano, P., Tol, R.S., 2018. Temperature shocks, short-term growth and poverty thresholds: evidence from rural tanzania. World Development 112, 13-32.

Masson-Delmotte, V., Zhai, P., Pörtner, H.O., Roberts, D., Skea, J., Shukla, P.R., Pirani, A., Moufouma-Okia, W., Péan, C., Pidcock, R., et al., 2018. Global warming of $1.5 \mathrm{c}$. An IPCC Special Report on the impacts of global warming of 1, 1-9.

Olmstead, A.L., Rhode, P.W., 2011. Adapting north american wheat production to climatic challenges, 1839-2009. Proceedings of the National Academy of sciences 108, 480-485.

Orlov, A., Sillmann, J., Aunan, K., Kjellstrom, T., Aaheim, A., 2020. Economic costs of heat-induced reductions in worker productivity due to global warming. Global Environmental Change 63, 102087.

Pachauri, R.K., Allen, M.R., Barros, V.R., Broome, J., Cramer, W., Christ, R., Church, J.A., Clarke, L., Dahe, Q., Dasgupta, P., et al., 2014. Climate change 2014: synthesis report. Contribution of Working Groups I, II and III to the fifth assessment report of the Intergovernmental Panel on Climate Change. Ipcc.

Parsons, K., 2007. Human thermal environments: the effects of hot, moderate, and cold environments on human health, comfort and performance. CRC press.

Polsky, C., Neff, R., Yarnal, B., 2007. Building comparable global change vulnerability assessments: The vulnerability scoping diagram. Global environmental change $17,472-485$. 
Ramsey, J.D., Kwon, Y.G., 1992. Recommended alert limits for perceptual motor loss in hot environments. international Journal of industrial Ergonomics 9, 245-257.

Roberts, M.J., Schlenker, W., 2013. Identifying supply and demand elasticities of agricultural commodities: Implications for the us ethanol mandate. American Economic Review 103, 2265-95.

Russo, S., Sillmann, J., Sterl, A., 2017. Humid heat waves at different warming levels. Scientific reports $7,1-7$.

Sachs, J.D., 2003. Institutions don't rule: direct effects of geography on per capita income.

Sadiq, L.S., Hashim, Z., Osman, M., 2019. The impact of heat on health and productivity among maize farmers in a tropical climate area. Journal of environmental and public health 2019.

Schlenker, W., Hanemann, W.M., Fisher, A.C., 2006. The impact of global warming on us agriculture: an econometric analysis of optimal growing conditions. Review of Economics and statistics 88, 113-125.

Sesmero, J., Ricker-Gilbert, J., Cook, A., 2018. How do african farm households respond to changes in current and past weather patterns? a structural panel data analysis from malawi. American Journal of Agricultural Economics 100, 115-144.

Somanathan, E., Somanathan, R., Sudarshan, A., Tewari, M., 2021. The impact of temperature on productivity and labor supply: Evidence from indian manufacturing. Journal of Political Economy 129, 1797-1827.

Wilkinson, J., Audsley, E., 2013. Options from life-cycle analysis for reducing greenhouse gas emissions from crop and livestock production systems. International Journal of Agricultural Management 2, 70-80.

Willett, K.M., Sherwood, S., 2012. Exceedance of heat index thresholds for 15 regions under a warming climate using the wet-bulb globe temperature. International Journal of Climatology 32, 161-177.

Xia, Y., Li, Y., Guan, D., Tinoco, D.M., Xia, J., Yan, Z., Yang, J., Liu, Q., Huo, H., 2018. Assessment of the economic impacts of heat waves: a case study of nanjing, china. Journal of Cleaner Production 171, 811-819.

Zander, K.K., Mathew, S., 2019. Estimating economic losses from perceived heat stress in urban malaysia. Ecological economics 159, 84-90.

Zhang, P., Deschenes, O., Meng, K., Zhang, J., 2018. Temperature effects on productivity and factor reallocation: Evidence from a half million chinese manufacturing plants. Journal of Environmental Economics and Management $88,1-17$.

Zhang, W., Li, Y., Li, Z., Wei, X., Ren, T., Liu, J., Zhu, Y., 2020. Impacts of climate change, population growth, and urbanization on future population exposure to long-term temperature change during the warm season in china. Environmental Science and Pollution Research 27, 8481-8491. 